\title{
ERRATA
}

\section{Prevalence and Risk Factors for Depressive Symptoms in Persons with Chronic Obstructive Pulmonary Disease}

\author{
Rebecca E. Schane, MD ${ }^{7,3}$, Louise C. Walter, $M D^{2}$, Alexis Dinno, SCD, MPH, MEM ${ }^{3}$, \\ Ken E. Covinsky, MD, MPH', and Prescott G. Woodruff, MD, MPH \\ 'Department of Medicine, Division of Pulmonary-Critical Care Medicine, the Cardiovascular Research Institute, University of California, \\ San Francisco, USA; ${ }^{2}$ Department of Medicine, Division of Geriatrics, San Francisco VA Medical Center, University of California, San Francisco, \\ USA; ${ }^{3}$ Department of Medicine, Center for Tobacco Control Research and Education, the Cardiovascular Research Institute, \\ University of California, San Francisco, USA
}

J Gen Intern Med 23(11):1930

DOI: $10.1007 / \mathrm{s} 11606-008-0773-z$

(c) Society of General Internal Medicine 2008

In their article, the order of the authors was listed as follows:

Authors: Rebecca E. Schane, $\mathrm{MD}^{1,3}$ Prescott G. Woodruff, $\mathrm{MD}^{1}$ Alexis Dinno, ScD, MPH MEM ${ }^{3}$ Ken E. Covinsky, MD, $\mathrm{MPH}^{2}$ Louise C. Walter, $\mathrm{MD}^{2}$

${ }^{1}$ Department of Medicine, Division of Pulmonary-Critical Care Medicine, the Cardiovascular Research Institute, University of California, San Francisco

${ }^{2}$ Department of Medicine, Division of Geriatrics, San Francisco VA Medical Center, University of California, San Francisco

${ }^{3}$ Department of Medicine, Center for Tobacco Control Research and Education, the Cardiovascular Research Institute, University of California, San Francisco

The order of the authors was incorrect. It should have read:

Authors: Rebecca E. Schane, $\mathrm{MD}^{1,3}$, Louise C. Walter, $\mathrm{MD}^{2}$, Alexis Dinno, ScD, MPH, MEM ${ }^{3}$, Ken E. Covinsky, MD, $\mathrm{MPH}^{2}$, and Prescott G. Woodruff, MD, $\mathrm{MPH}^{1}$

${ }^{1}$ Department of Medicine, Division of Pulmonary-Critical Care Medicine, the Cardiovascular Research Institute, University of California, San Francisco

${ }^{2}$ Department of Medicine, Division of Geriatrics, San Francisco VA Medical Center, University of California, San Francisco

${ }^{3}$ Department of Medicine, Center for Tobacco Control Research and Education, the Cardiovascular Research Institute, University of California, San Francisco

The online version of the original article can be found at http://dx.doi. org/10.1007/s11606-008-0749-Z

Published online September 12, 2008 